\title{
Editorial
}

\section{The Australian and New Zealand Intensive Care Research Centre}

\author{
Rinaldo Bellomo Amanda Martin David James Cooper \\ Monash University, School of Public Health and Preventive Medicine, Alfred Centre, Commercial Rd, Melbourne, \\ Victoria, Australia
}

The Australian and New Zealand (ANZ) Intensive Care Research Centre (ANZIC-RC) is the Australian National Health and Medical Research Council (NHMRC) and Monash University funded bi-national centre for the development, coordination and execution of multicentre randomized controlled trials (RCTs) in critically ill patients. The output for the ANZIC-RC in this field has led to major changes in the practice of critical care medicine in ANZ and the world, improved patient outcomes and has lowered the cost of health care. In addition, the ANZIC-RC has operated and continues to operate as a major national teaching centre for doctoral, post-doctoral and international clinician researchers in critical care medicine. Finally, it provides methodological, statistical, trial design and logistical assistance to young investigators in ANZ who wish to develop their understanding and career in the field of critical care clinical research.

The ANZIC-RC is located within the School of Public Health and Preventive Medicine of Monash University in its campus at the Alfred Centre (fig. 1) close to the centre of the city of Melbourne and adjacent to the campus of the Alfred Hospital, the major trauma centre in Australia (fig. 2).

The ANZIC-RC's director is Prof. David James (Jamie) Cooper, and Prof. Rinaldo Bellomo assists him as co-director. The ANZIC-RC's governance relies on regular supervision and meetings of a Board, which includes representatives from Monash University, the Australian and New Zealand Intensive Care Society (ANZICS) Clinical Trials Group (CTG), ANZICS, ANZICS Centre for Out- come Research and Evaluation (CORE) and the ANZ College of Intensive Care Medicine (CICM). It has a research staff of approximately 20 researchers and administrators and is involved in the supervision of between 10 and $15 \mathrm{PhD}$ students at any given time. It cooperates with more than 20 eminent or emerging researchers in ANZ who hold positions of adjunct professor or other adjunct appointments. Similarly, it conducts research in collaboration with eminent or emerging international investigators from France, Finland, Ireland, Saudi Arabia, the United Kingdom, the USA, and Canada with more than 20 such adjunct appointments. Finally, it conducts an advanced training program of yearly rotating senior research fellowships for rapidly emerging world-class young investigators.

In 2014, the ANZIC-RC conducted research in almost every aspect of critical care medicine with $>20$ active grants administered to support multiple projects and $>30$ grants with ANZIC-RC staff members, adjuncts or affiliates as investigators. Its success in obtaining grants from the NHMRC for specific research projects or centres for excellence development is shown in figure 3.

The publication record of the ANZIC-RC has been outstanding and has been progressively increasing every year since its inception (fig. 4), culminating in the delivery of 134 publications in 2014, of which 121 represented original articles and the presentation of $>200$ lectures at $>100$ national and international scientific meetings. ANZIC-RC researchers have repeatedly pub-

\section{KARGER}

E-Mail karger@karger.com

www.karger.com/bpu (c) 2015 S. Karger AG, Basel

0253-5068/15/0413-000I\$39.50/0
Prof. Rinaldo Bellomo

Australian and New Zealand Intensive Care Research Centre

School of Public Health and Preventive Medicine

Monash University, Melbourne, Victoria (Australia)

E-Mail rinaldo.bellomo@monash.edu 
Fig. 1. The Alfred Centre where the ANZIC-RC is situated.
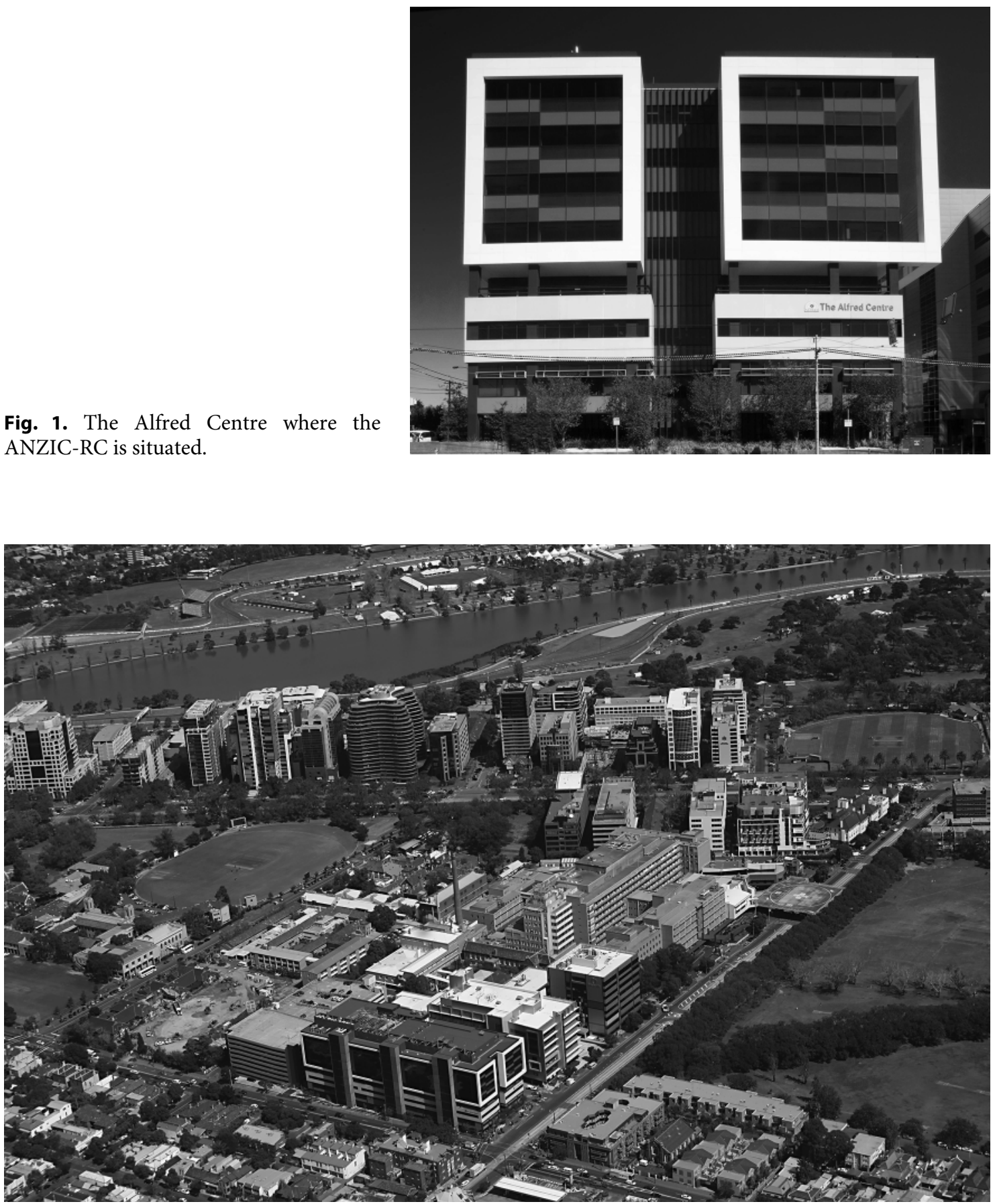

Fig. 2. The Monash University and Alfred Hospital Campus where the Alfred Centre is located.

Fig. 5. A wide angle shot of investigators and support staff at the ANZIC-RC.

Fig. 6. Members of the ANZIC-RC team celebrating Prof. Bellomo's achievement of 1,000 publications.

(For figures 5 and 6 see next page.) 


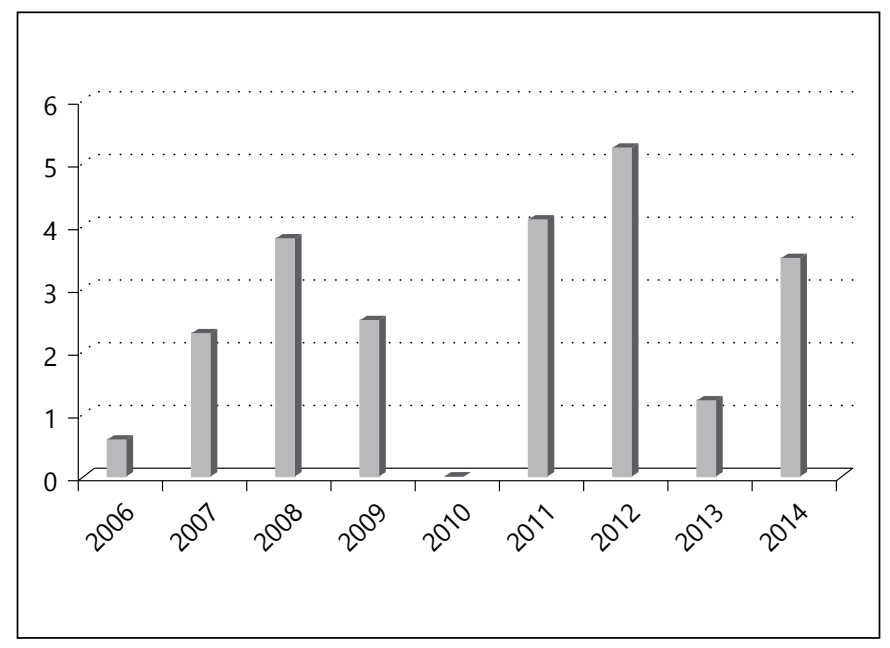

Fig. 3. ANZIC-RC's NHMRC in millions of dollars in the year approved.

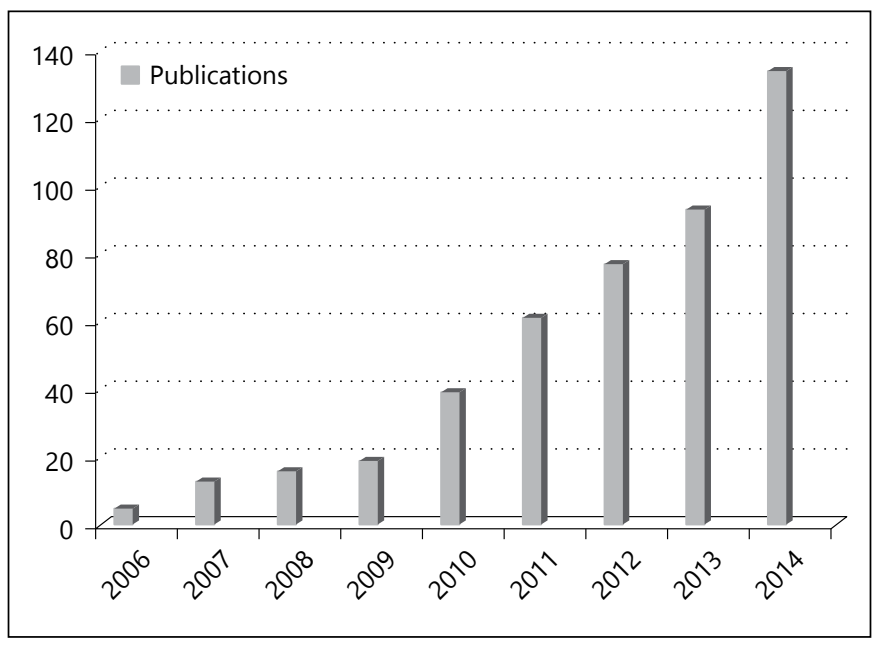

Fig. 4. Number of publications produced by the ANZIC-RC each year since its development (not cumulative).
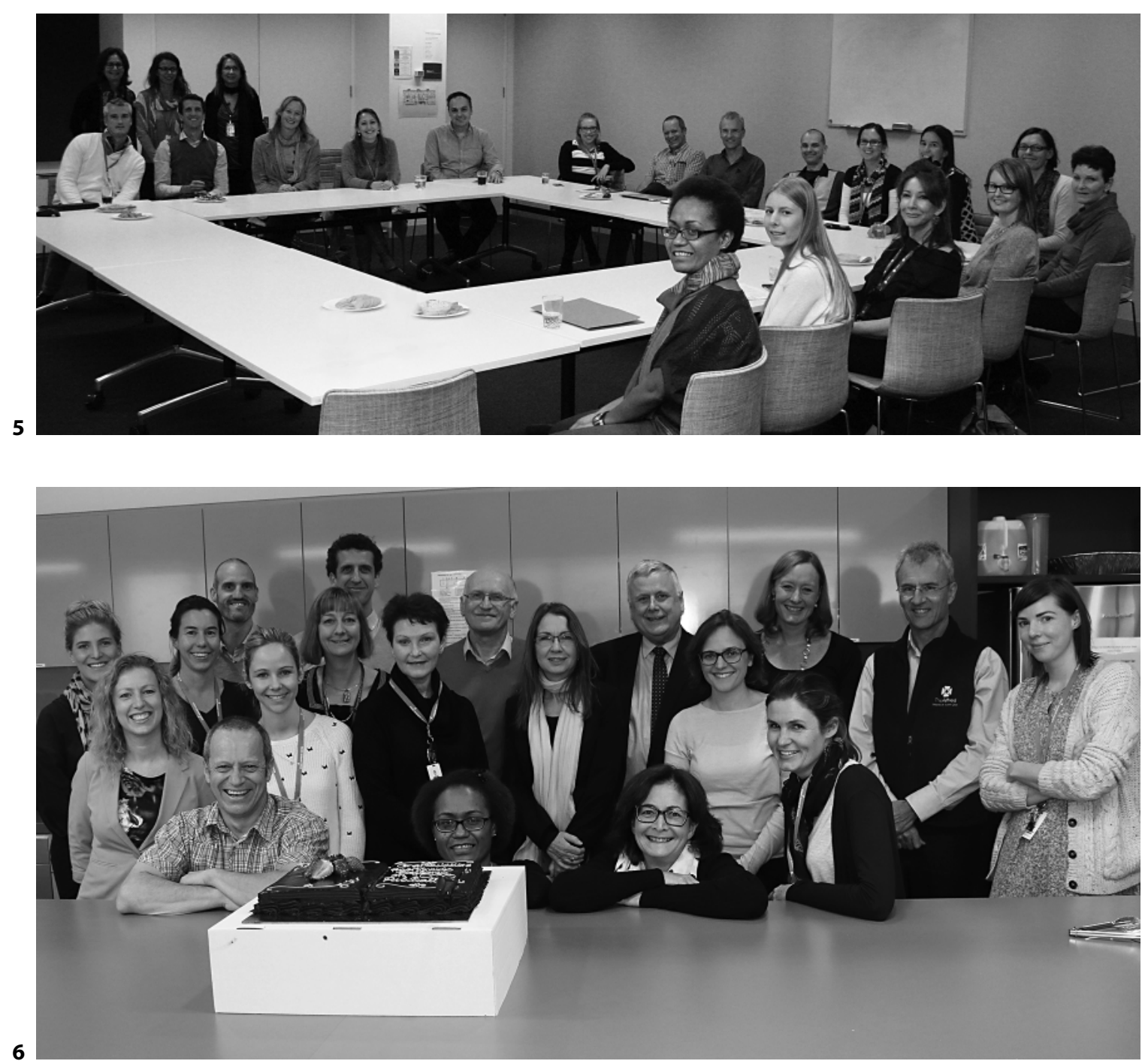
lished and regularly published such work in the most impactful journals in the world (New England Journal of Medicine, Lancet, JAMA) because a significant component of the work represents the final output of large multicentre, international, pivotal, RCTs. Such research has generated landmark studies published in the New England Journal of Medicine like the DECRA [1] study of decompressive craniectomy in patients with severe traumatic brain injury, the ARISE [2] study of resuscitation of septic patients with early goal directed therapy as well as key observational studies of the H1N1 influenza pandemic [3] or the limitations of the systemic inflammatory response syndrome criteria in defining sepsis in ICU [4].

At the same time it has promoted work by local investigators with publications in specialty journals as part of programs aimed at helping such investigators develop a record of academic achievement in clinical research [513]. As a consequence, studies published by ANZIC-RC investigators generate $>5,000$ citations per year. More importantly, the ANZIC-RC is currently conducting several international, multicentre, pivotal RCTs [14-18] which, when completed, will have randomized $>14,000$ patients; this will be the largest suite of such trials in critical care medicine in the world.

The ANZIC-RC contributes to dedicated research meetings such as those conducted by the ANZICS-CTG and has been crucial to the development of the research methodology training program initially conducted in Australia and then recently exported to Europe ('The Fine Art of Clinical Trials Course').

Finally, the ANZIC-RC now organizes a regular meeting, in Prato (Italy) within the Italian Campus of Monash University, dedicated to multicentre trials in critical care medicine ('Collaborative Clinical Trials in Intensive Care Medicine Conference').

Despite its extraordinary achievements over a decade and its commitment to international collaborations, the ANZIC-RC remains unmistakably antipodean in its values, lack of formality, free-exchange of open and frank opinions, exuberance, forthright expression of personality and enjoyment of friendship and humour (fig. 5 and 6). It is this unique atmosphere, which combines productivity with enjoyment that continues to attract people from all over the world while delivering a unique highest level research output.

\section{References}

1 Cooper DJ, Rosenfeld JV, Murray L, et al: Decompressive craniectomy in diffuse traumatic brain injury. N Engl J Med 2011;364:14931502.

2 Peake SL, Delaney A, Bailey M, et al: Goaldirected resuscitation for patients with early septic shock. N Engl J Med 2014;371:14961506.

3 Webb SA, Pettilä V, Seppelt I, et al: Critical care services and $2009 \mathrm{H} 1 \mathrm{~N} 1$ influenza in Australia and New Zealand. N Engl J Med 2009;361:1925-1934.

4 Kaukonen KM, Bailey M, Pilcher D, Cooper DJ, Bellomo R: Systemic inflammatory response syndrome criteria in defining severe sepsis. N Engl J Med 2015;372:1629-1638.

5 Bihari S, Festa M, Peake SL, Seppelt IM, Williams P, Wilkins B, Bersten A: Sodium administration in critically ill paediatric patients in Australia and New Zealand: a multicentre point prevalence study. Crit Care Resusc 2014; $16: 112-118$.

6 Eastwood GM, Litton E, Bellomo R, Bailey MJ, Festa M, Beasley RW, Young PJ: Opinions and practice of stress ulcer prophylaxis in Australian and New Zealand intensive care units. Crit Care Resusc 2014;16:170-174.

7 Litton E, Baker S, Erber W, et al: The IRONMAN trial: a protocol for a multicentre randomised placebo-controlled trial of intravenous iron in intensive care unit patients with anaemia. Crit Care Resusc 2014; 16:285-290.

8 Litton E, Eastwood GM, Bellomo R, et al: A multicentre feasibility study evaluating stress ulcer prophylaxis using hospital-based registry data. Crit Care Resusc 2014;16:158163.

9 Parke RL, McGuinness SP, Gilder E, McCarthy LW: Intravenous fluid use after cardiac surgery: a multicentre, prospective, observational study. Crit Care Resusc 2014;16:164-169.

10 Reddy SK, Bailey MJ, Beasley RW, et al: A protocol for the $0.9 \%$ saline versus Plasma-Lyte 148 for intensive care fluid therapy (SPLIT) study. Crit Care Resusc 2014;16:274-279.

11 Bannard-Smith J, Alexander P, Glassford N, et al: Haemodynamic and biochemical responses to fluid bolus therapy with human albumin solution, $4 \%$ versus $20 \%$, in critically ill adults. Crit Care Resusc 2015;17:122128.

12 Bihari S, Peake SL, Prakash S, Saxena M, Campbell V, Bersten A: Sodium balance, not fluid balance, is associated with respiratory dysfunction in mechanically ventilated patients: a prospective, multicentre study. Crit Care Resusc 2015;17:23-28.

13 Lipcsey M, Chiong J, Subiakto I, Kaufman MA, Schneider AG, Bellomo R: Primary fluid bolus therapy for infection-associated hypotension in the emergency department. Crit Care Resusc 2015;17:6-11.

14 Presneill J, Little L, Nichol A, et al: Statistical analysis plan for the erythropoietin in traumatic brain injury trial: a randomised controlled trial of erythropoietin versus placebo in moderate and severe traumatic brain injury. Trials 2014;15:501.

15 Nichol A, Gantner D, Presneill J, et al: Protocol for a multicentre randomised controlled trial of early and sustained prophylactic hypothermia in the management of traumatic brain injury. Crit Care Resusc 2015;17:92-100.

16 Shehabi Y, Bellomo R, Reade MC, et al: Early goal-directed sedation versus standard sedation in mechanically ventilated critically ill patients: a pilot study. Crit Care Med 2013;41: 1983-1991.

17 Peake SL, Chapman MJ, Davies AR, et al: Enteral nutrition in Australian and New Zealand intensive care units: a point-prevalence study of prescription practices. Crit Care Resusc 2012;14:148-153.

18 Kaukonen KM, Bailey M, Ady B, et al: A randomised controlled trial of standard transfusion versus fresher red blood cell use in intensive care (TRANSFUSE): protocol and statistical analysis plan. Crit Care Resusc 2014;16: 255-261. 